\title{
Burnout, Depression, Efficacy Beliefs, and Work-Related Variables among School Teachers
}

\begin{abstract}
The present study investigated burnout and its associated factors in school teachers. We tested the relationships between burnout, depression, efficacy beliefs (self and collective), school climate, and organizational justice in a sample of 609 Italian school teachers. Using path analysis and controlling for age and gender, we found that collective efficacy, school climate, and organizational justice were significantly associated with burnout and depression. The relationships between these variables and depression were mediated by burnout. Results suggest that planning development programs to reduce teachers' malaise and improve their evaluation methods involves taking into account the buffering effect of efficacy beliefs, school climate, and organizational justice against burnout and depression.
\end{abstract}

Keywords: burnout; depression; organizational justice; efficacy beliefs; teachers 


\section{Burnout, Depression, Efficacy Beliefs and Work-Related Variables among School}

\section{Teachers}

\section{Introduction}

Burnout and depression are important aspects of teachers' psychological health that can lead to negative personal and work outcomes. A strong association is found between teacher burnout and depression (Bakker et al., 2000; Schonfeld \& Bianchi, 2016), and they were found to share similar work-related antecedents (Toker \& Biron, 2012). The aim of the present study was to investigate and elucidate the relationships between teacher burnout, depression and perceptions of the work environment. We tested both self and collective efficacy beliefs, as well as teachers' perception of school climate and organization justice. Previous research has found that teacher burnout was related to efficacy beliefs (Skaalvik \& Skaalvik, 2007, 2010), perceived fairness at work (Kausto, Elo, Lipponen, \& Elovainio, 2005), school climate (Grayson \& Alvarez, 2008). We wished, thus, to expand on the psychosocial model, particularly by using burnout as a mediator between these work and self-perception variables and depression as a key indicator of the psychological well-being of teachers.

Burnout is a complex phenomenon, which involves individual, organizational and institutional aspects. According to Maslach, Schaufeli, and Leiter (2001, p. 397), burnout is a "prolonged response to chronic emotional and interpersonal stressors on the job". From the psychosocial perspective, burnout consists of three components: emotional exhaustion, a feeling of cynicism, and a sense of personal and professional inefficiency (Maslach et al., 2001). Of these three components, Schaufeli and Salanova (2007) considered emotional exhaustion and cynicism (or depersonalization) as the most central features of burnout. Burnout can impact on personal and work outcomes, as it may encompass reduced personal or professional accomplishments as expressed in negative emotions and cognitions about one's own achievements and capacities to succeed at work or in life in general (Schaufeli, Bakker, \& Van Rhenen, 2009). Schaufeli and 
Enzmann (1998) reported that teachers had the highest levels of emotional exhaustion compared to other professions. This is important to note, as burnout is a chronic issue that can undermine the quality of teachers' performance and impact their interactions with students, resulting in negative outcomes for students' performance (Gerber, Whitebook, \& Weinstein, 2007; Grayson \& Alvarez, 2008; Merida-López \& Extremera, 2017).

The Areas of Worklife (AW) model frames job stressors in terms of person-job imbalances, or mismatches, and identifies six key areas in which these imbalances take place: workload, control, reward, community, fairness, and values (Maslach \& Leiter, 2006). Research has since affirmed the model (e.g., Santavirta, Solovieva, \& Theorell, 2007; Simbula, Panari, Guglielmi, \& Fraccaroli, 2012), and the findings point to the importance of considering teachers' perceptions of and satisfaction with their work condition and environment such as their perceptions of fairness at work. Van Horn, Schaufeli, and Enzmann (1999) have also demonstrated that one of the sources of stress most frequently reported by teachers is equity. In unjust situations, burnout increases and engagement decreases. Skaalvik and Skaalvik (2007) analyzed the relationship between burnout and efficacy beliefs, external control, and strain factors in Norwegian teachers. They highlighted that the two dimensions of burnout, emotional exhaustion, and cynicism, were differently related to school context variables (i.e., discipline, teachers' feeling of having autonomy regarding the choice of teaching methods, teachers' feeling of having cognitive and emotional support from the school leadership, external control), and to self- and collective efficacy. The study revealed a particularly strong correlation between teacher self-efficacy and the dimensions of teacher burnout. Perceived collective teacher efficacy, instead, was not directly related to burnout dimensions, but there was a moderate indirect relation between perceived collective teacher efficacy and burnout that was mediated through teacher self-efficacy. Emotional exhaustion was positively related to behavioral problems and conflict with parents among students, and depersonalization was positively related to external control. 
Individual consequences of burnout include physiological, psychological, and psychosocial problems. Prior studies have shown that teacher burnout is significantly related to mental illness, especially depression (Schaufeli \& Greenglass, 2001; Schonfeld, 2001; Zurlo, Pes, \& Siegrist, 2010). The present study aimed to investigate the relationship between teachers' burnout, depression, efficacy beliefs, perceived organizational justice, and school climate while controlling for the effects of age and gender. In the next paragraphs we briefly discuss the key predictors used in the study and their link to burnout and depression.

\subsection{Burnout and Depression}

Similar to burnout, depression is one of the psychological strains that may represent a maladaptive reaction to life stressors. Many symptoms of burnout including fatigue, withdrawal, difficulty in relaxing when being out of work, and feelings of diminished enthusiasm, are also characteristic symptoms of depression (Bakker et al., 2000). Furthermore, burnout and depression share similar work-related antecedents (Toker \& Biron, 2012). In a recent study across 18 US States, Schonfeld and Bianchi (2016) found teachers' burnout to strongly correlate with depression, leading the authors to assume a conceptual overlap between these two variables. Similarly, in a cross-sectional study, burnout was shown to be related to depression among teachers (Bakker et al., 2000). The direction of causality seems to be running from burnout to depression. For example, Hakanen, Schaufeli, and Ahola (2008), using a panel design in a representative sample of Finnish workers, found that burnout predicted depression and not vice versa. In a three-wave study, an increase in job burnout was found to predict an increase in depressive symptoms (Hakanen \& Schaufeli, 2012). Similarly, a longitudinal study with teachers in Korea found that initial levels of teachers' burnout led to subsequent depression symptoms 18 months later (Shin, Noh, Jang, Park, \& Lee, 2013).

Moreover, when burnout and depression were analyzed with reference to job strain, it was found that burnout always mediated the path from job strain to depressive symptoms (Ahola \& Hakanen, 2007; Leiter, Bakker, \& Maslach, 2014). Hakanen et al.'s (2008) study found that burnout 
mediated the impact of different job demands and lack of job resources on depressive symptoms. Studies have also shown that burnout mediates the relationship between psychosocial factors and health (Bakker, Demerouti, De Boer, \& Schaufeli, 2003; Schaufeli \& Bakker, 2004). In line with these results, we expected that the dimensions of burnout would mediate the relationship between psychosocial work environment variables and teacher's depression.

\subsection{Efficacy Beliefs}

Efficacy beliefs represent key cognitions that may protect workers against the negative outcomes of job stress (Bandura, 2006; Brown, 2012). According to social cognitive theory, selfefficacy makes a difference in how people think, feel, and act (Bandura, 1997). It determines how environmental facilities and stressors are perceived, and how they influence people's goals, values, and behaviors (Bandura, 1997). A number of studies across countries show that high teacher selfefficacy predicts lower levels of burnout (Avanzi et al., 2013; Brown, 2012; Schwarzer \& Hallum, 2008; Skaalvik, \& Skaalvik, 2007; 2010; Yu et al., 2015) and depression (Kim \& Kim, 2010). Based on these findings, it is reasonable to hypothesize that teacher self-efficacy will be negatively related to emotional exhaustion, cynicism and, depression.

A related concept that also deserves attention is collective teacher efficacy, which refers to the beliefs that teachers, as a group, are able to successfully execute the courses of action required to produce given outcomes at school and influence the performance of their students (Skaalvik \& Skaalvik, 2009). Collective teacher efficacy has been considered as an important predictor in explaining differences in teacher success (Bruno, \& Converso, 2018; Goddard, Hoy, \& Woolfolk, 2000; Guidetti, Viotti). Bandura (1997) ranked collective teacher efficacy as the most important factor influencing student achievement. Teachers' beliefs "in their collective efficacy influence the type of future they seek to achieve, how they manage their resources, the plans and strategies they construct, how much effort they put into their group endeavour, their staying power when collective efforts fail to produce quick results or encounter forcible opposition, and their vulnerability to discouragement" (Bandura, 1997, p. 478). Teachers characterized by high collective efficacy set 
optimally challenging goals, and are persistent in their efforts to achieve these goals (Tschannen Moran, Woolfolk Hoy, \& Hoy, 1998). Studies have found that low levels of collective efficacy beliefs are associated with high burnout and depression in teachers (Authors, 2016; Yang \& Farn, 2005). In our study, we thus tested for both self-efficacy and collective self-efficacy beliefs and their association with burnout and depression.

\subsection{School Climate}

Although school climate is often considered an important research topic in the school contexts, there is no universal agreement on how it should be defined (Thapa, Cohen, Guffey, \& Higgins-D'Alessandro, 2013). Considering school climate as “the psychosocial context in which teachers work and teach" (Johnson, Stevens, \& Zvoch, 2007, p. 834), we concentrate on teachers' perceptions of it. Research has revealed that different aspects of school climate are related to burnout dimensions. Grayson and Alvarez (2008), for example, found that worse student-peer relationships and less community involvement (aspects of school climate) were associated with higher levels of emotional exhaustion (a burnout dimension) among teachers. Additionally, teachers' dissatisfaction with school administration is predictive of cynicism and negative attitudes towards students. On the other hand, 'positive relations with colleagues', which is a dimension of school climate, has been shown to be negatively related to burnout in elementary school and middle school teachers (Droogenbroeck, Spruyt, \& Vanroelen, 2014). Lim and Eo (2014) also found that teachers' successful dialogue with colleagues, as a measure of school organizational climate, was also associated with lower levels of teacher's burnout. Finally, factors related to teacher relationships with other members of the school system (students, parents, the administration) were highly related to depersonalization (Droogenbroeck et al., 2014; Petrillo \& Donizzetti, 2013), and unfavorable working climate was found to be associated with poor mental health such as anxiety and depression (e.g., Bellingrath, Weigl, \& Kudielka, 2009). We aimed to investigate this further, and test whether school climate dimensions as perceived by teachers relate negatively to burnout (emotional exhaustion, cynicism) and depression. 


\subsection{Organizational Justice}

Organizational justice is important for analyzing many organizational outcome variables (Greenberg, 1990). In the AW model, fairness is reflected as the extent to which decisions at work are perceived as being fair and equitable (Maslach \& Leiter, 2006). Employees draw on the quality of the procedures, and their own treatment during the decision-making process, as an index of their place in the community. Cynicism is likely to arise when people feel they are not being treated with respect (Maslach, 2004). In the school context, perceived justice is a crucial concept for both teachers and students. It is an influential factor in creating a peaceful and harmonious workplace (Buluc and Gunes, 2014). Several studies have shown that organizational justice is a key factor in defining social and psychological atmosphere in organizations (Authors, 2013; Authors, 2015; 2016). Unfair work conditions can lead to a lack of perceived control, or social exclusion, contributing to teacher burnout (Kausto et al., 2005). A study involving high school teachers found that organizational relationships characterized by a lack of equity in the ratio of investments in the relationship with the school and outcomes from students were related to higher burnout levels (Van Horn et al., 1999). We, therefore, hypothesized organizational justice to be negatively related to emotional exhaustion and cynicism.

Perceptions of organizational justice have also been found to be associated with negative emotional states, and inversely with depression, stress, and anxiety (Elovainio, Kivimäki, \& Vahtera, 2002; Judge \& Colquitt, 2004; Spell \& Arnold, 2007). For example, a longitudinal threewave study among a representative sample of 1519 employees in a Dutch population confirmed that organizational justice (as measured by distributive and procedural justice) was related to the absence both of depressive symptoms and sickness (Ybema \& Van Den Bos, 2010). In line with such findings, we expected to find a significant and negative relationship between organizational justice beliefs and depression.

\subsection{Age and Gender}


Studies on the relationship between the levels of burnout and age (Maslach et al., 2001; Schaufeli, Bakker, \& Salanova, 2006) have yielded inconclusive results (Brewer \& Shapard, 2004). For instance, a study found that older teachers reported lower emotional exhaustion and higher perceived personal accomplishment than younger teachers (Droogenbroeck et al., 2014), whereas other studies have revealed non-significant associations between burnout and age (Van Der Doef \& Maes, 2002). With regard to gender, few studies have reported statistically significant differences in the levels of burnout. Even when the relationship was significant, they tend to be rather weak (Schaufeli et al., 2006; Schaufeli \& Greenglass, 2001). Some studies have shown that female teachers are more susceptible to burnout than males. For example, Ahola, Hakanen, Perhoniemi, and Mutanen (2014) found higher levels of burnout in female teachers, whereas, for depressive symptoms, older teachers were more likely to report higher levels. However, the nature and type of work need to be taken into account in research examining gender differences in burnout, as men and women often occupy different occupational roles, which could lead to difficulties with discerning the effects of gender from occupation type (Schaufeli \& Greenglass, 2001). In sum, the results of the studies on teacher depression and burnout are usually mixed and inclusive (Beer \& Beer, 1992). Although the effects of age and gender on burnout and depression of teachers may be not strong, these variables need to be controlled for research on burnout and depression, considering that in certain contexts they may play more pronounced roles.

\subsection{Aim and Hypotheses}

Teachers work in a complex environment where many different factors may lead to poor psychological health, such as high levels of burnout and depression. Such factors include low teacher self-efficacy, low school collective efficacy, job dissatisfaction, and lack of administrative support (Gu \& Day, 2013; Kyriacou, 2000; Skaalvik \& Skaalvik, 2007, 2010, 2011). Additionally, research indicates that one of the sources of stress most frequently reported by teachers is inequity (Van Horn, Schaufeli, \& Enzmann, 1999). In unjust situations, burnout increases and engagement decreases. In the present study, we employed a broad approach for assessing the psychosocial work 
environment of teachers. The studies reviewed above have already introduced models in which the relationships between some of these variables and burnout have been investigated. However, recent systematic reviews and meta-analyses propose that some components of burnout may show differential associations with these variables (Shoji et al., 2016; Brown, 2012).

Furthermore, few studies have simultaneously included personal and collective efficacy beliefs, and school climate in the same model (Skaalvik \& Skaalvik, 2007) and, to our knowledge, there are no studies that have simultaneously tested the effect of these variables and organizational justice, even though this would have been reasonable considering the strong influence that the latter has on burnout (see AW model, Maslach, 2004; Maslach \& Leiter, 2016). In a recent systematic review on physical, psychological, and occupational consequences of job burnout, Salvagioni et al. (2017) showed that burnout frequently results in depressive symptoms. Hence, we aimed at testing the relationships among all these variables, exploring the associations between the dimensions of teachers' burnout, depression and efficacy beliefs, organizational justice and school climate, while taking into account the effects of age and gender.

Based on the previous findings (e.g., Hakanen et al., 2008; Leiter et al., 2014), we aimed to examine whether dimensions of burnout mediated the relationship between the variables included in the study and depression, and make the following predictions:

\section{Hypothesis 1.}

The burnout dimensions would be negatively related to efficacy beliefs, perceived school organizational climate and organizational justice.

\section{Hypothesis 2.}

Depression would be negatively related to efficacy beliefs, perceived school organizational climate and organizational justice

\section{Hypothesis 3.}


Efficacy beliefs, school climate, and organizational justice would be negatively and indirectly related to depression, through the intervening variables of emotional exhaustion and cynicism

\section{Methods}

\subsection{Participants}

A sample of 609 schoolteachers from Italian public schools participated in this study. They were between the age of 27 and 65 with a mean age of 48.35 years ( $S D: 8.50)$. Of the participants, $73.5 \%$ had over 10 years of teaching experience and $76.2 \%$ were female. Gender distribution is consistent with national level statistics showing that the most of all compulsory schooling teachers in Italy are female (ISTAT, 2016). In Italy, attending school is compulsory until the age of 16. Most participants worked in high school $(44.5 \%), 27.7 \%$ of teachers worked in middle school, $16.1 \%$ in elementary and $11.6 \%$ in primary school. All the participants taught at schools with class sizes of an average of 24 students.

\subsection{Measures}

Depression. The Center for Epidemiologic Studies Depression Scale (Italian version by Fava, 1983) measures symptoms of depression in community populations. The scale consists of 20 items (e.g. "I felt that everything I did was an effort"). Participants are asked to report how often they have felt each symptom during the past week on a scale from rarely or none of the time, less than 1 day (0), to most or all of the time; 5-7 days (3).

Burnout. The Italian version of the Maslach Burnout Inventory-General Scale (Borgogni, Galati, Petitta, \& Centro Formazione Schweitzer, 2005) was used to assess job burnout (Maslach, Jackson, \& Leiter, 1996). In the present study only two aspects of burnout, namely emotional exhaustion (5 items, "I feel burned out from my work") and cynicism ( 5 items, "I have become less

enthusiastic about my work"), were included because they are typically considered the most central features of burnout (for a review, see Maslach et al., 2001). Emotional exhaustion is described as the feeling of being emotionally drained by one's work. Cynicism is a pessimistic or excessively 
detached response to the work itself and/or to the individuals with whom teachers interact while performing their job. All of the items were rated on a 7-point scale ranging from never (0) to always (6).

Self-efficacy. The Teacher Self-efficacy Scale (Borgogni, Galati, \& Petitta, 2001), consists of nine items measuring teachers' beliefs in their ability to effectively handle various tasks, obligations, and challenges related to their professional role (e.g. "How much can you do to get students to believe they can do well in school work?"; "I can make my students respect rules and codes of conduct"). Each item was rated on a 7-point response format, ranging from nothing (1) to a great deal (7).

Collective efficacy. The School Collective Efficacy Scale (Borgogni et al., 2001), is comprised of nine items measuring teachers' personal perceptions of their school's collective capabilities to influence student achievement, and it is based on teachers' analysis of teaching staff's capabilities to effectively teach all students (e.g. "Our school is able to fully achieve the objectives of school autonomy reforms; Teachers in this school are confident they will be able to motivate their students"). Teachers rated, on a 7-point scale, their agreement with each statement, from strongly disagree (1) to strongly agree (7).

School Climate. School climate was assessed using the three subscales of opportunities and school participation, school organizational relationships, and discipline from the Scholastic Situation Questionnaire - Teacher Version (Santinello \& Bertarelli, 2002). Opportunities and school participation (e.g., "In my school there is the possibility to use well-equipped laboratories") as well as School organizational relationships (e.g., "The principal takes into account the opinion of the teachers in the decision making") were each measured by ten items. School organizational relationships refers to the quality of relationships between teachers, headmaster, and students, and gives some information on the social and emotional climate of the school. Discipline was measured by six items (e.g., "Students respect the rules"), measuring the extent to which teachers and students 
respect the rules, as well as the frequency of incidents of violence. All items were scored on a 4point frequency rating scale ranging from 1 ("completely false") to 4 ("completely true").

Organizational justice. To measure teachers' perceptions of fairness in the operation and administration of their schools, we used the Italian version of the Organizational Justice Index (Hoy \& Tarter, 2004; Authors, 2016), consisting of 10 items (e.g., "The principal does not play favorites; and "Educators in this school follow courses of action that are generally free of self-interest"). Respondents were asked to describe the behavior of teachers and administrators using a 6-point scale, ranging from 1 ("strongly disagree") to 6 ("strongly agree").

\subsection{Procedure}

Researchers obtained a convenience sample of teachers from Italian public schools. We used a snowball sampling that relied on referral from initial participants (through word-of-mouth) to generate additional participants. A researcher, expert in Health Psychology, personally distributed the questionnaires to the teachers on an individual basis. The questionnaires were completed in the presence of the researcher to address possible questions and concerns of the participants. With the exception of 44 teachers, all participants agreed to complete the questionnaire. The survey took about 20-30 minutes to complete. Teachers received an explanation of the study aims and reassurance of its anonymity and confidentiality. They were also informed that their responses would solely be used for the purposes of academic research. The data were collected during the first four months of the school year (September - January 2016, and September - January 2017). The study was conducted following the APA (2010) ethical guidelines. In accordance with the legal requirements of the study country (Italy), no additional ethical approval was required because no patients were involved. Also, no treatment, including medical, invasive diagnostics, or procedures causing psychological or social discomfort, was administered to the participants.

\subsection{Statistical Analysis}

Path models were tested in Mplus 8 separately for each predictor with two mediators. In all of the models, maximum likelihood was used. A minimum cutoff point of .95 for Comparative Fit 
Index (CFI), a maximum cutoff of .07 for Root Mean Square Error of Approximation (RMSEA), and a maximum cutoff of .08 for Standardized Root Mean Square Residual (SRMR) were considered as indicative of acceptable fit (e.g., Brown, 2015). The full information maximum likelihood (FIML) method was used to handle missing data. We repeated the analyses with listwise deletion and the results were highly similar to the FIML results. Therefore, only FIML results are reported. In all of the analyses, we included gender $($ male $=0$, female $=1)$ and age as covariates predicting depression and the two mediators. Considering that the results of three ANOVAs showed that school level was not a significant predictor of depression $F(3,599)=.585, p=.625$, emotional exhaustion $F(3,607)=.064, p=.979$, or disaffection $F(3,613)=1.654, p=.176$, it was not included in the mediation analyses as a covariate.

We calculated $95 \%$ non-symmetric bias-corrected bootstrap confidence intervals (10000 replications) for all parameters in our models, including indirect effects. Using bootstrap confidence intervals is highly recommended for testing hypotheses concerning indirect effects (Hayes, 2013; Jose, 2013; Muthén, Muthén, \& Asparouhov, 2016), given that indirect effects are in fact products of parameters, and usually have non-normal distributions. Considering that we found non-linear relationships between the variables in some of the mediational triangles, Hayes and Preacher's (2010) method for testing nonlinear mediation was used to take into account the nonlinear nature of the mediational patterns for these variables. In such cases, because the mediator changes nonlinearly as the predictor changes, and the outcome changes nonlinearly as the mediator changes, there is no single indirect effect that characterizes the predictor's indirect influence on the outcome through the mediator. Instead, we need to estimate indirect effects of the predictor at particular values of the predictor (usually, the mean of the predictor, as well as plus and minus one $S D$ from the mean). These indirect effects are called instantaneous indirect effects of the predictor on the outcome. Instantaneous indirect effects indicate the strength of the mediation at various values of the predictor (Hayes \& Preacher, 2010).

\section{Results}


Internal consistencies and the correlations between all of the variables used in the study are presented in Table 1. Except cynicism, with an Alpha coefficient of .66, all other scales obtained internal consistency values higher than .70 . The results of correlation analyses provide support for our first two hypotheses. That is, the predictors are negatively related to both burnout and depression. Our initial analyses indicated that for opportunities, organizational relationships, and organizational justice, no nonlinear relationship was involved in the mediation triangles. Therefore, for these three predictors, we used linear mediation analysis (Hayes, 2013). We started with a saturated model for each predictor where there were no left-out directional paths. Saturated models yield no fit indices. It is generally recommended to prune from the model the non-significant directional paths involving the covariates (Little, 2013). However, the directional paths between the predictor, mediator, and outcome are not dropped even when they are not significant (Darlington \& Hayes, 2016). Accordingly, for each predictor, non-significant direct effects of age and gender were dropped one at a time in a series of models, which led to the final model for each predictor. The fit indices and parameter estimates of the final models are reported in Table 2. As shown, the models fitted the data very well. The good model fit obtained suggests that the estimates and standard errors of the model are trustworthy (Muthén et al., 2016). Given that the bootstrap confidence intervals for the six indirect effects did not include zero, all of the six indirect paths can be considered significant. In other words, emotional exhaustion and cynicism functioned as significant mediators between the three predictors (i.e., opportunities, organizational relationships, and organizational justice) and depression.

In our initial analyses, we found quadratic relationships in the mediation triangles related to discipline, collective efficacy, and self-efficacy. Specifically, there were significant quadratic relationships between discipline and cynicism, self-efficacy and depression, and collective efficacy and emotional exhaustion. Therefore, we used a procedure for examining indirect effects suitable in the presence of nonlinearity following guidelines from Hayes and Preacher (2010). This analysis is largely similar to a linear mediation analysis, with the quadratic term of the predictor also included 
in the analysis. Multiple indirect effects (i.e., instantaneous indirect effects of the predictor) were calculated. Using the conventional "representative values" strategy, in the present analyses, the mean value of the predictor, as well as plus and minus one $S D$ from the mean were used (Hayes \& Preacher, 2010). We employed the similar model trimming strategy used for the linear mediation analyses. Following Hayes and Preacher (2010), we report unstandardized estimates for nonlinear mediations. The model fit indices, unstandardized estimates, and bootstrap confidence intervals are presented in Table 3. The models provided an excellent fit to the data, and zeroes were not included in the confidence intervals of all of the indirect paths.

For discipline, the instantaneous indirect effects indicated that at higher values of discipline, the indirect path through cynicism was weaker. The instantaneous indirect effects of discipline through emotional exhaustion, however, were largely similar in strength, indicating that nonlinearity had a small influence on the mediational results. The indirect path from collective efficacy through emotional exhaustion was stronger at higher values of collective efficacy. The indirect path from collective efficacy through cynicism also becomes slightly stronger at higher values of collective efficacy. Finally, the indirect paths from self-efficacy through cynicism and emotional exhaustion were slightly different at various values of self-efficacy. Thus, the results were consistent with our hypotheses and showed that emotional exhaustion and cynicism mediated the relationship between the three predictors (i.e., discipline, collective efficacy, and self-efficacy) and depression. The results of our nonlinearity-adjusted mediation analyses revealed that the sizes of the indirect effects were different at various levels of the predictors. However, these differences were small in magnitude and consistent in direction. Therefore, nonlinearity can be generally considered of limited influence on our conclusions. Together, these results provide support for our third hypothesis, which predicted an intervening role of the dimensions of burnout.

\section{Discussion}

The present study examined the relationships among teachers' perceived work environment, efficacy beliefs, and depression in a single model with burnout as a mediator. We expected that the 
dimensions of school organizational climate, efficacy beliefs, and perceived organizational justice would predict depression partially or fully through the intervening variables of emotional exhaustion and cynicism. The results were consistent with our expectations. Most importantly, we found support for all of our hypotheses. The linear mediation analysis showed that emotional exhaustion and cynicism functioned as significant mediators between opportunities, organizational relationships, organizational justice and depression. Furthermore, nonlinear mediation analyses suggested that emotional exhaustion and cynicism significantly mediated the relationships between discipline, collective efficacy, self-efficacy, and depression. The results are promising and suggest that future research should consider various ways to improve these variables with the aim of protecting against depression in school contexts.

Many studies have shown that organizational justice is related to the health and well-being of people at work. Our results were in line with the prior empirical evidence; we found that justice perceptions could lead to positive outcomes for teachers in school contexts, preventing burnout and depression. Our findings thus have implications for the education sector, highlighting the importance of creating a positive and fair work environment for teachers (Cropanzano \& Ambrose, 2001). Furthermore, teachers should be encouraged to participate in decision-making processes and engage in different academic activities, so that they feel or recognize that their contribution to school is important (Srivastava, 2017).

In line with previous studies (Lauermann \& König, 2016; Skaalvik \& Skaalvik, 2007), teacher self-efficacy was significantly and negatively associated with teacher burnout and, via its relationship to the burnout dimensions, indirectly with depression. Self-efficacy had a nonlinear relationship with depression. This relationship is positive at lower levels of self-efficacy and negative at higher levels of self-efficacy. We used nonlinear mediation analysis to consider this nonlinear relationship between the two variables. The positive relationship between the two variables in the path model can also be seen as "suppression". Suppression occurs when a variable (in this case self-efficacy) receives a positive weight when controlling for other variables in the 
model, whereas it has a negative zero-order correlation with the outcome variable (Darlington \& Hayes, 2016). Suppression may occur when the predictors and mediators are correlated. The present results show that the negative relationship between self-efficacy and depression is specific to teachers' work context (rather than attributable to teachers' general life domains). Thus, teacher self-efficacy has the potential to serve as a protective factor against depression only indirectly, via its negative associations with burnout dimensions.

Our findings also indicated a clear relationship between collective efficacy and the dimensions of burnout, as well as a strong relationship between collective efficacy and teachers' depression, in line with previous studies (Bandura, 1997; Authors, 2016). These findings suggest that actions need to be taken to raise group efficacy perceptions for reducing the general level of depression and burnout in teachers. Goddard and Skrla (2006) argued that the stronger a group's collective efficacy beliefs, the more likely that its members will put forth the sustained effort and persistence towards the shared goals. According to Bandura (1993, p.177), "faculties' beliefs in their collective instructional efficacy contribute significantly to their schools' level of academic achievement". Hence, boosting teachers' confidence in their capability as a collective seems to be essential for increasing their overall well-being, and improving the school's performance.

Furthermore, positive relations with colleagues and superior are very important in building shared values and norms and create a collective goal orientation. Borrowing from both Goddard et al. (2000) and Skaalvik and Skaalvik (2007), we employed individually-perceived collective teacher efficacy without aggregation by organization. However, collective efficacy is an emergent grouplevel attribute (Bandura, 1997). Thus, further studies should also examine the contribution of teacher's collective beliefs at the school level, focusing on global indicators of school functioning. Additional studies should also include a measure of organizational efficacy that captures the domain-specific aspects of school efficacy for a deeper understanding of this variable in school contexts. 
We found that all the dimensions of school climate (albeit in different ways) were negatively related to burnout and depression. The results showed that emotional exhaustion and cynicism significantly mediated the relationships between discipline and depression. Discipline problems, as a dimension of school climate, are documented as a serious work-related stressor, and are identified as important sources of teacher burnout (Montgomery \& Rupp; 2005; Skaalvik \& Skaalvik 2010). Our results suggest that discipline is one of the most significant aspects of school climate with consequences both for burnout and depression, requiring special attention from policymakers. Educational policymakers need to consider creating cooperative and supportive school climates, and more work is needed to better understand this issue. Qualitative research techniques, such as observation or interview, can be utilized for gaining a richer understanding of the relations between burnout and school climate (Natale, Di Martino, Procentese, \& Arcidiacono, 2016).

Our findings also demonstrated that school organizational relationships as a dimension of school climate affected burnout and, both directly and indirectly, depression. As can be seen from Table 1, organizational relationships and organizational justice were closely related, similarly to previous studies (e.g., Guy \& Di Paola, 2008). However, they represented different aspects of the school environment. Organizational justice refers to the perceptions of fairness in the operation and administration of schools, including interactional (aspects of the communication process between the source and the recipient of justice), and distributive and procedural justice aspects (Rutter \& Maughan, 2002). School organizational relationships refer to the quality of relationships between teachers, headmaster, and students, giving information on the social and emotional climate of the school. In other words, the quality of the relations with colleagues and students is an aspect that may affect both organizational justice and relationships, and yet, organizational justice and relationships form distinct constructs that may have different contributions to the prediction of burnout and depression. A close examination of the results suggests that both organizational justice and relationships are relevant indicators to consider when investigating teachers' experience. Altogether, our results provide some support to the Areas of Worklife (AW) model, as psychosocial 
work-related variables such as perceived organizational justice impacted on the psychological health of the teachers.

Since the school type (e.g., elementary, middle and high school) was not a significant predictor of any of the mediators or the outcome, it was not included in the mediation analyses as a covariate. These results are similar to those presented in the literature review (Devos, Dupriez, \& Paquay, 2012). The job demands-resources model (Demerouti et al., 2001) suggests that structural aspects of the school, such as large school size, age of students, challenge the school's functioning, and stability increase demands on teachers which in turn is likely to affect teachers' efficacy and burnout (Authors, 2016; Avanzi et al., 2018; Hoy, Tarter, \& Bliss, 1990). Additional research is needed with various set of schools, in order to further explore potential contextual influences on burnout and depression.

Our findings revealed that women displayed higher depression and exhaustion than man. A possible explanation is that maintaining a balance between work and family life may be more complicated and challenging for women, considering women's traditional role in managing the household. A heavier household workload may contribute to the increased burnout and depression. Age, on the other hand, did not affect burnout dimensions which is in line with Van Der Doef and Maes (2002). Yet, age was positively predictive of depression. The different age ranges of the participants across studies may explain these inconsistencies in these findings (Schaufeli \& Enzmann, 1998).

\section{Limitations}

A number of limitations of the present research should also be highlighted. Firstly, the study is cross-sectional. Thus, the results are basically correlational analysis, and causality cannot be inferred. Future longitudinal studies should tap into the causal nature and the stability of the investigated relationships. Such studies would allow for much stronger inferences. Secondly, the present study was exclusively based on self-reported data, and not immune to common method bias. Therefore, it is important for future studies to strive to assess these variables using independent 
sources of information. Future research could include, for instance, physician-diagnosed depression, register-based job retention, and other non-self-report measures of job conditions. These would reduce common method variance and offer additional confidence in testing our hypotheses. Furthermore, in line with previous studies (Bria et al., 2014) the burnout cynicism scale yielded a low internal consistency (.66). However, given that all other scales had acceptable alphas, the value was not considered as threatening to the validity of the study results (Loewenthal, 2004).

Thirdly, the type of recruiting did not permit to obtain school-specific information within a multilevel analysis framework, but this approach should be considered in future research. A large number of participating schools would be necessary to adequately examine organizational effects and test the generalizability of our results across school contexts. Furthermore, although our sample is representative of the gender composition of the Italian compulsory schooling teachers, it is not well balanced by gender, so the results concerning the effects of gender are not sufficiently generalizable. However, in a recent research with Italian teachers, it was found that more relevant than teachers' gender were their years of experience (Fiorilli et al., 2017). In future studies, the number of years in the teaching profession should be also taken into account. Finally, because of the difficulty of recruiting respondents through the Italian Department of Public Education, we used a convenient sample. Although the sample is relatively large, it is not representative of the Italian teacher population. In future studies, a larger and more representative sample should be used.

\section{Implications and Conclusion}

Our findings provide some useful insights. First, by differentiating the roles played by the different dimensions of burnout, we provide additional support for the notion that emphasizes the significance of organizational antecedents of burnout. Second, our study examined burnout as a mediator of the relationship between organizational variables and depression. Altogether, these findings contribute to the ongoing debates in health and work psychology about the nature of the association between burnout and depression. As suggested by Schonfeld, and Bianchi (2016), given the achievement of the burnout among the scientific community, clarifying the nature of this 
syndrome has become an important topic in health psychology, occupational medicine, and psychiatry. The results of our study suggest that burnout and depression are related but distinct concepts (Bakker et. al, 2000), considering their moderate associations (Table 1; large amount of non-shared variance between depression and burnout is up to 80\%) and differential set of predictors (the final model). So, we believe considering these variables as distinct is statistically and theoretically justifiable. These results suggest that cynicism and emotional exhaustion impact on depression, but they are clearly distinguishable from depression. Findings contribute to the ongoing debates in psychology about the nature of the association between burnout and depression (Schonfeld and Bianchi, 2016), suggesting that burnout and depression are related but distinct concepts (Authors 2018; Schaufeli and Enzmann, 1998). We suggest that further studies with confirmatory factor analysis could provide support for differentiating burnout and depression. Investigating the temporal relationship between burnout and depressive symptoms could also add to be better understanding of the association between these concepts.

This study contributes to the existing literature by emphasizing the risk factors associated with burnout. Our findings pinpoint the importance of imparting teachers with personal social and organizational skills in order to promote well-being and cope better with burnout and depression. They highlight the value of monitoring and managing job burnout among teachers in order to reduce teachers' depression. School managers should also take measures to reduce it, such as reinforcing efficacy beliefs, ensuring a supportive working environment, and increasing good relationships between school members. These insights can be utilized to plan appropriate preventive interventions. Educational policymakers and researchers in teacher education need to develop various teacher education programs and managerial changes aimed at reducing the levels of burnout.

Our results underscore the importance of facilitating teachers' collective efficacy to prevent burnout. When teachers perceived their collective effectiveness as optimally high, they were more unlikely to suffer from burnout. Hence, teachers who suffer from burnout should be helped to 
improve their collective efficacy and regain their faith in their group's effectiveness. Thus, facilitating collective efficacy might be a useful management strategy in school contexts (Salanova et al., 1999). Additionally, perceived justice seems to have a buffering effect against burnout. It is therefore important that school principals make an effort to reduce injustice in work situations for teachers. That will require a thorough analysis of the roles and responsibilities of teachers, how teaching is organized, as well as acknowledging teachers' needs for different types of resources and support (Cano-Garcìa, Padilla-Muñoz, \& Carrasco-Ortiz, 2005).

Finally, our results show that teachers with higher levels of burnout are more likely to report higher levels of depression. This is consistent with prior research showing that burnout leads to a range of psychological and physical health problems, including anxiety, depression, sleep disturbance, memory impairment, and neck pain (Peterson et al., 2008). Our results underline the role of work-related psychosocial constructs such as collective efficacy, organizational justice and school climate for mental health. Depressive symptoms can also develop from strains in other domains of life, but these findings show that depressive symptoms are correlated with important work-related variables. Thus, facilitating and maintaining positive work experiences in school contexts core may be an effective way to combat teacher depression. This could, in turn, have important consequences for teachers' motivation and students' well-being, as well as on teachers' work-family balance.

\section{References}

Ahola, K., Hakanen, J., Perhoniemi, R., \& Mutanen P. (2014). Relationship between burnout and depressive symptoms: a study using the person-centred approach. Burnout Research, 1, 2937. 
Ahola, K., Honkonen, T., Isometsä, E., Kalimo, R., Nykyri, E., Aromaa, A., \& Lönnqvist, J. (2005).The relationship between job-related burnout and depressive disorders - results from the Finnish Health 2000 Study. Journal of Affective Disorders, 88, 55-62.

American Psychological Association. (2010). The publication manual of the American psychological association (6 ${ }^{\text {th }}$ ed.). Washington, DC: American Psychological Association.

Authors (2013). [details removed for peer review]

Authors (2015) [details removed for peer review]

Authors (2016) [details removed for peer review]

Authors (2018) [details removed for peer review]

Avanzi, L., Fraccaroli, F., Castelli, L., Marcionetti, J., Crescentini, A., Balducci, C., \& van Dick, R. (2018). How to mobilize social support against workload and burnout: The role of organizational identification. Teaching and Teacher Education, 69, 154-167.

Avanzi, L., Miglioretti, M., Velasco, V., Balducci, C., Vecchio, L., Fraccaroli, F., \& Skaalvik, E. M. (2013). Cross-Validation of the Norwegian Teacher's Self-Efficacy Scale (NTSES). Teaching and Teacher Education, 31, 69-78.

Bakker, A. B., Demerouti, E., De Boer, E., \& Schaufeli, W.B. (2003). Job demands and job resources as predictors of absence duration and frequency. Journal of Vocational Behavior, 62, 341-56.

Bakker, A. B., Schaufeli, W. B., Demerouti, E., Janssen, P. P. M., Van Der Hulst, R., \& Brouwer, J. (2000). Using equity theory to examine the difference between burnout and depression. Anxiety, Stress \& Coping, 13, 247-268.

Bandura, A. (1993). Perceived self-efficacy in cognitive development and functioning. Educational Psychologist, 28, 117-148.

Bandura, A. (1997). Self-efficacy: The exercise of control. New York: Freeman

Bandura, A. (2006). Toward a psychology of human agency. Perspectives on Psychological Science, 1, 164-180. 
Beer, J., \& Beer, J. (1992). Burnout and stress, depression and self-esteem of teachers. Psychological Reports, 71(3 Pt 2), 1331-1336.

Bellingrath, S., Weigl, T.,\& Kudielka, B.M. (2009) Chronic work stress and teachers. Stress, 12, 3748.

Borgogni, L., Galati, D., Petitta, L., \& Centro Formazione Schweitzer (2005). Il questionario Checkup organizzativo. Manuale dell'adattamento italiano. [The Organizational Checkup Questionnaire. Manual of the Italian Version] Firenze: O.S. Organizzazioni Speciali. Borgogni, L., Pettita, L., \& Steca, P. (2001). Efficacia personale e collettiva nei contesti organizzativi. [Personal and collective beliefs in organizational contexts]. In G.V. Caprara (Ed.), La valutazione dell'autoefficacia. Interventi e contesti culturali (pp. 157-171) [The assessment of self-efficacy. Interventions and cultural contexts]. Trento: Edizioni Erickson.

Brewer E.W., \& Shapard, L.(2004). Employee burnout: A meta-analysis of the relationship between age or years of experience. Human Resource Development Review, 3, 102-123.

Bria, M., Spânu, F., Băban, A., Dumitraşcu, D.L., Adriana, B., Dumitras, D.L. (2014). Maslach burnout inventory-general survey: factorial validity and invariance among Romanian healthcare professionals. Burnout Research, 1(3), 103-111.

Brown, C.G. (2012). A systematic review of the relationship between self-efficacy and burnout in teachers. Educational \& Child Psychology, 29, 47-63.

Brown, T.A. (2015). Confirmatory factor analysis for applied research. New York, NY: Guilford Press.

Buluc, B., \& Gunes, A.M. (2014). Relationship between organizational justice and organizational commitment in primary schools. Anthropologist, 18, 145-152.

Cano-García, F.J., Padilla-Muñoz, E.M., \& Carrasco-Ortiz, M.A. (2005). Personality and contextual variables in teacher burnout. Personality and Individual Differences, 38, 929-940.

Cohen, J., McCabe, L., Michelli, N.M., \& Pickeral, T. (2009). School climate: Research, policy, practice, and teacher education. Teachers College Record, 111, 180-213. 
Cropanzano, R. \& Ambrose, M.L. (2001). Procedural and Distributive Justice are More Similar than you Think: A Monistic Perspective and a Research Agenda, in: J. Greenberg \& R. Cropanzano (Eds.), Advances in Organizational Justice (pp. 119-151). Stanford: Stanford University Press.

Darlington, R. B., \& Hayes, A. F. (2016). Regression analysis and linear models: Concepts, applications, and implementation. New York: Guilford Publications.

Demerouti, E., Bakker, A.B., Nachreiner, F., \& Schaufeli, W. (2001). The job demands-resource model of burnout. Journal of Applied Psychology, 86, 499-512.

Devos, C., Dupriez, V., \& Paquay, L.(2012) Does the social working environment predict beginning teachers' self-efficacy and feelings of depression?. Teaching and Teacher Education, 28, 206217

Droogenbroeck, F.V., Spruyt, B., \& Vanroelen, C. (2014). Burnout among Senior Teachers: Investigating the Role of Work- load and Interpersonal Relationships at Work. Teaching and Teacher Education, 43, 99-109.

Elovainio, M., Kivimäki, M., \& Vahtera, J. (2002). Organizational justice: evidence of a new psychosocial predictor of health. American Journal of Public Health, 92, 105-108.

Fava, G.A. (1983). Assessing depressive symptoms across cultures: Italian validation of the CES-D self-rating scale. Journal of Clinical Psychology, 39, 249-251.

Fiorilli, C., Albanese, O. , Gabola, P., \& Pepe A.(2017). Teachers' Emotional Competence and Social Support: Assessing the Mediating Role of Teacher Burnout. Scandinavian Journal of Educational Research, 61(2), 127-138.

Gerber, E.B., Whitebook, M., \& Weinstein, R.S. (2007). At the heart of child care: Predictors of teacher sensitivity in center-based child care. Early Childhood Research Quarterly, 22, 327346.

Goddard, R.D., \& Skrla, L. (2006). The influence of school social composition on teachers'collective efficacy beliefs. Educational Administration Quarterly, 42, 216-235. 
Goddard, R.D., Hoy, W.K., \& Woolfolk, A. (2000). Collective teacher efficacy: Its meaning, measure, and effect on student achievement. American Education Research Journal, 37, 479507.

Grayson, J.L., \& Alvarez, H.K. (2008). School climate factors relating to teacher burnout: a mediator model. Teaching and Teacher Education, 24, 1349-1363.

Greenberg J., \& Colquitt J.A. (2005) (Eds.). Handbook of organizational justice. Mahwah, NJ: Lawrence Erlbaum.

Greenberg, J. (1990). Looking fair vs. being fair: Managing impressions of organizational justice. In B.M. Staw \& L.L. Cummings (Eds.), Research in organizational behavior (pp. 11-157). Greenwich, CT: JAI Press.

Gu, Q. \& Day, C. (2013). Challenges to teacher resilience: conditions count. British Educational Research Journal, 39, 22-44.

Guidetti, G., Viotti, S., Bruno, A., \& Converso D. (2018) Teachers’ work ability: a study of relationships between collective efficacy and self-efficacy beliefs. Psychology Research and Behaviour Managagement, 11, 197-206.

Hakanen, J.J., Schaufeli, W.B., \& Ahola, K. (2008). The job demands-resources model: A three-year cross-lagged study of burnout, depression, commitment, and work engagement. Work \& Stress, 22, $224-241$.

Hakanen, J.J.,\& Schaufeli, W.B. (2012). Do burnout and work engagement predict depressive symptoms and life satisfaction? A three-wave seven-year prospective study. Journal of Affective Disorders, 141, 415-424.

Hayes, A. F., \& Preacher, K. J. (2010). Quantifying and testing indirect effects in simple mediation models when the constituent paths are nonlinear. Multivariate Behavioral Research, 45, $627-660$.

Hayes, A.F. (2013). Introduction to mediation, moderation, and conditional process analysis: A regression based approach. New York: The Guilford Press. 
Hoy, K.W. \& Tarter, C.J. (2004). Organizational justice in schools: No justice without trust, International Journal of Educational Management, 18, 250-259.

Hoy, W.K., Tarter, C.J., \& Bliss, J.R. (1990). Organizational health, school climate, and effectiveness: A comparative analysis. Educational Administration Quarterly, 26, 260-279.

Johnson, B., Stevens, J. J., \& Zvoch, K. (2007). Teachers' perceptions of school climate: A validity study of scores from the revised school level environment questionnaire. Educational and Psychological Measurement, 67, 833-844.

Jose, P.E. (2013). Doing statistical mediation and moderation. New York: The Guilford Press.

Judge, T.A., \& Colquitt, J.A. (2004). Organizational justice and stress: The mediating role of workfamily conflict. Journal of Applied Psychology, 89, 395-404.

Kausto, J., Elo, A.L., Lipponen, J., \& Elovainio, M. (2005). Moderating effects of job insecurity in the relationships between procedural justice and employee. well-being: gender differences. European Journal of Work and Organizational Psychology, 14, 431-452.

Kim Y.H., \& Kim Y.E. (2010). Korean early childhood educators' multi-dimensional teacher selfefficacy and ECE center climate and depression severity in teachers as contributing factors. Teaching and Teacher Education, 26(5), 1117-1123

Kyriacou, C. (2000). Stress busting for teachers. Cheltenham, U.K.: Stanley Thornes. Lauermann, F., \& König, J. (2016). Teachers’ professional competence and wellbeing: Understanding the links between general pedagogical knowledge, self-efficacy and burnout. Learning and Instruction, 45, 9-19.

Leiter, M.P., Bakker, A.B., \& Maslach, C. (2014). Burnout at work: A psychological perspective. Sussex: Psychology Press, Hove,

Lim, S., \& Eo, S. (2014). The mediating roles of collective teacher efficacy in the relations of teachers' perceptions of school organizational climate to their burnout. Teaching and Teacher Education, 44, 138-147.

Little, T.D. (2013). Longitudinal structural equation modeling. New York: Guilford Press. 
Malinen, O., \& Savolainen, H. (2016). The effect of perceived school climate and teacher efficacy in behavior management on job satisfaction and burnout: A longitudinal study. Teaching and Teacher Education, 60, 144-152.

Mérida-López, S., \& Extremera N. (2017). Emotional intelligence and teacher burnout: A systematic review. International Journal of Educational Research, 85, 121-130.

Maslach, C. (2004). Areas of worklife: a structured approach to organizational predictors of job burnout. In P.L. Perrewe. \& D.C. Ganster (Eds.), Research in occupational stress and wellbeing (pp. 91-134). Oxford: Elsevier.

Maslach, C., \& Leiter, M.P. (2016). Understanding the burnout experience: recent research and its implications for psychiatry. World Psychiatry, 15, 103-111.

Maslach, C., Schaufeli, W.B. \& Leiter, M.P. (2001). Job burnout. Annual Review of Psychology, 52, $397-422$.

Maslach,C., Jackson S.E., \& Leiter M.P. (1996). Maslach Burnout Inventory manual (3rd ed.), Consulting Psychologists Press.

Montgomery, C., \& Rupp, A. (2005). A meta-analysis for exploring the diverse causes and effects of stress in teachers. Canadian Journal of Education, 28, 461-488.

Muthén, B.O., Muthén, L.K., \& Asparouhov, T. (2016). Regression and mediation analysis using Mplus. Los Angeles, CA: Muthén and Muthén.

Natale, A., Di Martino, S., Procentese, F., \& Arcidiacono, C. (2016). De-growth and critical community psychology: Contributions towards individual and social well-being. Futures, 78$79,47-56$

Peterson, U., Demerouti, E., Bergström, G., Samuelsson, M., Asberg, M., \& Nygren, A. (2008). Burnout and physical and mental health among Swedish healthcare workers. Journal of Advanced Nursing, 62, 84-95. 
Petrillo G., \& Donizzetti A.R. (2013). Burnout degli insegnanti: Il ruolo protettivo dei fattori contestuali e delle percezioni riferite all'efficacia scolastica e alle risorse del territorio. Psicologia della salute, 2, 96-119.

Rutter, M., \& Maughan, B. (2002). School effectiveness findings 1979-2002. Journal of School Psychology, 40, 451-475.

Salvagioni, D.A.J, Melanda, F.N., Mesas, A.E., González, A.D., Gabani, F.L., \& Andrade S. (2017) Physical, psychological and occupational consequences of job burnout: A systematic review of prospective studies. PLOS ONE, 12, e0185781.

Santavirta, N., Solovieva, S., \& Theorell, T. (2007). The association of job strain and exhaustion in a cohort of 1,028 Finnish teachers. British Journal of Educational Psychology, 77, 213-228.

Santinello, M., \& Bertarelli, P. (2002). La scuola come setting. [School as setting] In M. Prezza \& M. Santinello (Eds.), Conoscere la comunità. L'analisi degli ambienti di vita quotidiana (pp. 257-296) [Knowing the community. Analysis of the everyday life environments]. Bologna: Il Mulino.

Schaufeli ,W.B., \& Enzmann, D. (1998). The burnout companion to study and research: A critical analysis. Taylor \& Francis, London.

Schaufeli, W.B., \& Greenglass, E.R. (2001). Introduction to special issue on burnout and health. Psychology \& Health, 16, 501-510.

Schaufeli, W.B., \& Salanova, M. (2007). Work engagement: An emerging psychological concept and its implications for organizations. In S.W. Gilliland, D.D. Steiner. \& D.P. Skarlicki (Eds.), Research in Social Issues in Management (Volume 5): Managing social and ethical issues in organizations. (pp. 135-177). Greenwich, CT: Information Age Publishers.

Schaufeli, W.B., Bakker, A.B. \& Salanova, M. (2006). The measurement of work engagement with a short questionnaire: A cross-national study. Educational and Psychological Measurement, 66, 701- 716. 
Schaufeli, W.B., Bakker, A.B., \& Van Rhenen, W. (2009). How changes in job demands and resources predict burnout, work engagement, and sickness absenteeism. Journal of Organizational Behavior, 30, 893-917.

Schonfeld, I., \& Bianchi, R. (2016). Burnout and depression: two entities or one. Journal of Clinical Psychology, 72, 22-37.

Schonfeld, I.S. (2001). Stress in 1st-year women teachers: The context of social support and coping. Genetic, Social, and General Psychology Monographs, 127, 133-168.

Schwarzer, R., \& Hallum, S. (2008). Perceived Teacher Self-Efficacy as a Predictor of Job Stress and Burnout: Mediation Analyses. Applied Psychology: An International Review, 57, 152171.

Shin, H., Noh, H., Jang, Y., Park ,Y.M, \& Lee S.M. (2013). A longitudinal examination of the relationship between teacher burnout and depression. Journal of Employment Counseling, 50, $124-137$.

Shoji, K., Cieslak, R., Smoktunowicz,E., Rogala, A. Benight, C.C., \& Luszczynska A. (2016). Associations between job burnout and self-efficacy: a meta analysis. Anxiety, Stress, \& Coping, 29, 367-86.

Simbula, S., Panari, C., Guglielmi D., \& Fraccaroli, F. (2012). Teachers' Well-being and Effectiveness: The Role of the Interplay between Job Demands and Job Resources. Procedia Social and Behavioral Sciences, 69, 729-738.

Skaalvik, E. M., \& Skaalvik, S. (2007). Dimensions of Teacher Self-Efficacy and Relations with Strain Factors, Perceived Collective Teacher Efficacy, and Teacher Burnout. Journal of Educational Psychology, 99, 611-625.

Skaalvik, E.M., \& Skaalvik, S. (2009). Does school context matter? Relations with teacher burnout and job satisfaction. Teaching and Teacher Education, 25, 518-524.

Skaalvik, E.M., \& Skaalvik, S. (2010). Teacher self-efficacy and teacher burnout: a study of relations. Teaching and Teacher Education, 26, 1059-1069. 
Skaalvik, E.M., \& Skaalvik, S. (2011). Teacher job satisfaction and motivation to leave the teaching profession: relations with school context, feeling of belonging, and emotional exhaustion. Teaching and Teacher Education, 27, 1029-1038.

Spell, C.S., \& Arnold, T. (2007). An appraisal perspective of justice, structure, and job control as antecedents of psychological distress. Journal of Organizational Behavior, 28, 729 -751.

Srivastava, A.P. (2017). Teachers' extra role behaviour: relation with self-efficacy, procedural justice, organizational commitment and support for training. International Journal of Management in Education, 11, 140-162.

Thapa, A., Cohen, J., Guffey, S., \& Higgins-D’Alessandro, A. (2013). A review of school climate research. Review of Educational Research, 83, 357-385.

Toker, S., \& Biron, M. (2012). Job burnout and depression: unraveling their temporal relationship and considering the role of physical activity. Journal of Applied Psychology, 97, 699-710.

Tschannen Moran, M., Woolfolk Hoy, A., \& Hoy, W. K. (1998). Teacher efficacy: Its meaning and measure. Review of Educational Research, 68, 202-248.

Van Der Doef, M., \& Maes, S. (2002). Teacher-specific quality of work versus general quality of work assessment: A comparison of their validity regarding burnout, (psycho)somatic wellbeing and job satisfaction. Anxiety, Stress and Coping, 15, 327-344.

Van Horn, J.E., Schaufeli, W.B., \& Enzmann, D. (1999). Teacher burnout and lack of reciprocity. Journal of Applied Social Psychology, 29, 91-108.

Yang, H.J., \& Farn, C.K. (2005). Investigation the factors affecting MIS student burnout in technicalvocational college. Computers in Human Behavior, 21, 917-932.

Ybema, J.F., \& Van den Bos, K. (2010). Effects of organizational justice on depressive symptoms and sickness absence: a longitudinal perspective. Social Science and Medicine, 70, 16091617. 
Yu, X., Wang, P., Zhai, X., Dai, H. \& Yang, Q. (2015). The effect of work stress on job burnout among teachers: The mediating role of self-efficacy. Social Indicators Research, 122, 701708.

Zurlo, M.C., Pes, D., \& Siegrist, J. (2010) Validity and reliability of the effort-reward imbalance questionnaire in a sample of 673 Italian teachers. International Archives of Occupational and Environmental Health, 83, 665-674. 